\title{
Food System Outcomes: An Overview and the Contribution to Food Systems Transformation
}

\author{
Lilliana Stefanovic $^{1 *}$, Barbara Freytag-Leyer ${ }^{2}$ and Johannes Kahl ${ }^{1}$ \\ ${ }^{1}$ Department of Organic Food Quality and Food Culture, Faculty of Organic Agricultural Sciences, University of Kassel, \\ Kassel, Germany, ${ }^{2}$ Department of Nutritional, Food and Consumer Sciences, Fulda University of Applied Sciences, Fulda, \\ Germany
}

\section{OPEN ACCESS}

Edited by: Lorena Soto-Pinto,

The South Border College (ECOSUR), Mexico

Reviewed by:

Liming Ye,

Ghent University, Belgium

Julius B. Adewopo,

International Institute of Tropical

Agriculture (IITA), Nigeria

Xavier Arnauld De Sartre,

Center National de la Recherche

Scientifique (CNRS), France

${ }^{*}$ Correspondence:

Lilliana Stefanovic

I.stefa@uni-kassel.de

Specialty section:

This article was submitted to Agroecology and Ecosystem Services,

a section of the journal

Frontiers in Sustainable Food Systems

Received: 27 March 2020

Accepted: 19 August 2020

Published: 24 September 2020

Citation:

Stefanovic L, Freytag-Leyer B and Kahl J (2020) Food System Outcomes: An Overview and the Contribution to Food Systems

Transformation.

Front. Sustain. Food Syst. 4:546167.

doi: 10.3389/fsufs.2020.546167
The interest in food system discourse has been increasing over time, however, the understanding of what makes a food system is still subject to variations depending on the research focus. While the earlier discourse was mainly value chain centered, the recent years have witnessed a shift in focus toward a more holistic view embracing the complex character of food systems. An indispensable component of the food systems approach are the food system outcomes that represent the results, or consequences, of the food system activities. This mini-review is based on a systematic literature review of food system outcomes and aims to provide an overview of the different discourses underpinning the food system outcomes while outlining the ones with a potential contribution to the transformation toward sustainable food systems. The variety of discourses spans from food (and nutrition) security and global environmental change to resilience and food system sustainability, potential performance assessments and metrics and, finally, the food systems transformation. Important outcomes within each of the discourses are highlighted and certain existing gaps are pointed out. While all discourses are essential for the overall understanding of the outcomes, these are certain commonalities in the discourses that bear synergetic potential for facilitating the transition to sustainable food systems.

Keywords: food system outcomes, food systems transformation, food systems performance, sustainability, resilience

\section{INTRODUCTION}

The food system (FS) discourse received increased attention in the past decade. It is recognized that food and agriculture are the cross-cutting elements of the 2030 Agenda of the United Nations connecting its 17 Sustainable Development Goals and helping to achieve multiple, if not all of them (EEA, 2017; FAO, 2018). However, the FS in the way it exists today is not sustainable due to the multitude of negative externalities it generates. Likewise, FS activities are largely responsible for detrimental environmental impacts-land change, loss of habitat and biodiversity, water, soil, and air pollution (Whitmee et al., 2015; UNEP, 2016; IPBES, 2019). Furthermore, contemporary FSs are a significant contributor to climate change, with a share of up to $29 \%$ of anthropogenic greenhouse gas emissions (Vermeulen et al., 2012). Additional pressure on ecosystems is added through unsustainable consumption patterns (Moscatelli et al., 2016). FSs also contribute to socio-economic inequalities, with negative implications for small-scale producers and vulnerable groups (Johns et al., 2013; Niles et al., 2017). Ultimately, even the normative purpose of feeding the world 
is not fulfilled. Although the global FS does produce enough food to meet the dietary needs of the population, 690 million people worldwide are hungry while $11 \%$ of the global population is undernourished (IPBES, 2019; FAO et al., 2020). It has been increasingly recognized that the FS needs to undergo a process of transformation to optimize its outcomes (Caron et al., 2018). To streamline the process of food systems transformation, it is crucial to apply the FSs approach taking into account the complexity of existing interactions and feedback mechanisms (Niles et al., 2017; Bortoletti and Lomax, 2019). A good starting point would be to gain better understanding about FS outcomes. This mini-review aims to shed light on the multitude of FS outcomes and uncover the broader discourses underpinning them while highlighting the ones of particular importance for the transformation process. The findings are based on a systematic literature review performed between November 2018 and April 2019. The publications of the past decade applying FSs approach have been considered for the review. The mini-review will begin with discussing the FSs approach and proceed with disclosing the FS outcomes along with the broader narratives framing them.

\section{FSs APPROACH AND THE CORNUCOPIA OF FSs}

FSs are in the spotlight of academic attention and political discussions, with the focus shifting toward recognition of the FSs potential for a transition toward sustainable development (Caron et al., 2018; FAO, 2018). Although the concept of FSs is not new, its interpretation and representation has been changing over time. Traditionally, the FS has been understood as a set of activities "from farm to fork," which equals it to supply chain activities or value chain (Ericksen, 2008; Chase and Grubinger, 2014; MacDonald and Reitmeier, 2017; Ruben et al., 2019). This corresponds to a linear representation, with linear understanding of linkages between supply-demand activities, where producers are on one side of the continuum and consumers-on the other (Ericksen, 2008; Chase and Grubinger, 2014; MacDonald and Reitmeier, 2017; Ruben et al., 2019). Adding waste management and nutrient recovery to the far end of the linear representation transferred the visualization of the FS to a circular model better capable of capturing the input-output linkages (Chase and Grubinger, 2014; Ruben et al., 2019). Finally, owing to non-linear interactions and complex dynamics of the FS, visualizations representing FSs as networks or webs have emerged (Chase and Grubinger, 2014; Ruben et al., 2019). By viewing the FS this way, farming systems or local FSs would all be considered subsystems within the overall FS (Ericksen, 2008; Chase and Grubinger, 2014; Eakin et al., 2017). At a subsystem level, a great variety of agricultural production and FSs can be found worldwide, some of them deemed important in the context of FS outcomes are outlined in Table 1. The concepts 10-12 in Table 1 represent a vital part of FSs approach enabling to take into account FSs' complexity and dynamic nature as well as the existence of non-linear interactions and feedback loops (Nesheim et al., 2015; Niles et al., 2017). A FS can be hence defined as all the activities from production to consumption, outcomes of these activities, drivers comprised of interactions within and between biogeophysical and human environments as well as interactions and feedbacks between them (Ericksen, 2008; Ericksen et al., 2010). The outcomes are a distinct component of this definition implying that any attempt to improve the FSs performance should begin with taking a closer look at the FS outcomes. The following sections seek to contribute to this endeavor.

\section{THE MULTITUDE OF FS OUTCOMES}

The FSs literature addresses the outcomes linking them to the FS activities referring to "what we get" (the outcomes) from "what we do" (FS activities) (Ingram, 2011; UNEP, 2016). Although the classification of FS outcomes varies from author to author, yet, regardless of the differences the outcome categories can generally be assigned to four broad groups: food and nutrition security (or health pillar) and the three pillars of sustainability, namely environmental, social and economic, which is the representation used by Niles et al. (2017). The earlier classification by Ericksen (2008) presented FS outcomes as contributions to food security, social welfare, and environmental security, with social welfare incorporating social and economic aspects, or determinants of food security (Ericksen, 2008). More recent publications differentiate between food and nutrition security, socio-economic and environmental outcomes (Bortoletti and Lomax, 2019). As the FSs literature was acquiring more sustainability-oriented and transformative character, new classifications emerged, for instance, the "desired" (Whitfield et al., 2015; Béné et al., 2019; Ruben et al., 2019) or "emergent" outcomes (Eakin et al., 2017), or, else, "intended" (Johns et al., 2013) or "expected" sustainable FS (SFS) outcomes (Bortoletti and Lomax, 2019).

\section{FS OUTCOMES IN THE VARIETY OF DISCOURSES}

To disclose the role of FS outcomes in the FSs transformation, the main thematic framings underpinning the outcomes have been identified using narrative synthesis as described by Petticrew and Roberts (2006). Six broader discourses were identified spanning from food (and nutrition) security and global environmental change to sustainability, the overall FSs performance, resilience, and, finally, transformation (see Table 2). The following sections provide a brief description of these discourses highlighting the corresponding outcomes.

\section{Food (and Nutrition) Security (FNS) and Global Environmental Change (GEC)}

Although FNS and GEC are two separate narratives, often they are handled concurrently due to the increased recognition of their interrelations. The vast majority of literature within these discourses considers FNS as a primary FS outcome (Ericksen, 2008; Ingram, 2011; Ingram et al., 2013; Allen et al., 2019). Food security is defined as a situation "when all people, at all times, have physical and economic access to sufficient, safe and nutritious food that meets their dietary and food preferences 
TABLE 1 | Selected agricultural and food systems, food system concepts, and their main characteristics.

\begin{tabular}{lll}
\hline $\mathbf{N}$ & $\begin{array}{l}\text { Type of system/ Brief description } \\
\text { food system } \\
\text { conceptualization }\end{array}$ & References \\
\hline
\end{tabular}

1 Agricultural production system

$2 \quad$ Integrated farming systems

3 Dynamic agricultural production system

4 Dynamic-integrated agricultural production system

$5 \quad$ Peasant farming systems

6 Industrialized agricultural/food system (FS)

7 Traditional FS

$8 \quad$ Agroecosystems

$9 \quad$ Agroecology

$10 \quad$ FS as social-ecological system (SES)

$11 \quad$ FS as dynamic system

12 FS as complex adaptive system
Production systems consisting of no more than two enterprises with minimal interactions between them, such as no resource flow. These systems include monocultures, polycultures, aquaculture, pastures, rangelands, mixed crop-livestock systems, agroforestry, and fallow lands.

Agricultural production systems that are typically mixed (both crops and livestock, or fish and trees), with multiple enterprises interacting to benefit from synergetic resource transfer. In such systems, outputs from one enterprise are used as inputs to another.

Agricultural production systems with a non-predetermined management characterized by annual strategy adjustments based on weather conditions, for instance. Producers may use production components in order to optimize the outcome of production, while maintaining input costs at minimum.

Horizontally integrated agricultural production systems with multiple enterprises interacting in time and/or space being managed in a dynamic way. Similar to integrated systems, there is synergetic resource transfer among the involved enterprises. Decision-making takes place annually and intra-annually based on management concerns, producers' goals as well as exogenous factors.

Farming systems of small producers that rely on traditional and subsistence farming methods, low use of chemical inputs and intensive labor. These systems are characterized by a diversity of crops through polycropping and integration of animals.

Agricultural system characterized by high urbanization, vertical integration and intensive farming, with large proportion of processing sector in the supply chain. Focus is on efficiency and specialization. The supply chains are long and organized. The diet is characterized by a low dependence on staples and high degree of processed foods.

FS characterized by its reliance mainly on locally grown foods, with people living in rural areas and growing much of their own food. Such systems have low external inputs and rely on naturally generated inputs and human knowledge. Production, processing, and trade occur at small scale and market infrastructure is limited. Consumption tends to correspond to seasonal harvests. Focus is placed on stability rather than yield maximization.

Agricultural ecosystems consisting of biophysical and human components as well as their interactions and providing agricultural products and rural services. Environment-production relationships of agriculture are represented in systems terms. One differentiates between three scales, or levels, of agroecosystems: micro-level (e.g., farm-level agroecosystem), meso-level (e.g., regional agroecosystem), and macro-level (e.g., global agroecosystem). Across levels agroecosystems might contain various components with distinctive interactions among them.

Change-oriented, transdisciplinary and participatory research and action bridging practice, science, and social movements. The core of this approach is the ecology of the entire FS incorporating ecological, social, and economic dimensions, with an emphasis on systems thinking. The focus in on ecological principles and holistic methods for designing and managing sustainable agroecosystems backed by indigenous farming knowledge. The existing power structures are challenged through a strong emphasis on food sovereignty that puts the needs and aspirations of local producers and consumers at the heart of FSs. Food sovereignty views hunger and food insecurity as a problem of access and distribution, largely due to inequality, and poverty. Food sovereignty prioritizes local and national markets and economies, promotes empowerment of peasants and family-farmed producers, transparent trade with fair prices and just incomes allowing a life with dignity for farmers, control over resources and land, right of consumers to control their food and define their FSs, with new social relations without inequality and oppression.

FS as a complex coupled human-natural system, containing subsystems (i.e., resource systems), resource units and users as well as governance systems. All components are relatively separable, while interacting to generate outcomes that in turn provide feedbacks to the subsystems.

FS as a complex system consisting of many interacting elements capable of changing over time. These elements function together as one collective unit. Integral characteristics are interdependence, interactions, and feedbacks loops. Food system outcomes emerge through complex interactions among FS elements.

FS as a system comprised of the multitude of heterogeneous components, whose interactions determine system behavior. These systems are characterized by individuality (various actors and institutions) and adaptation, presence of feedback mechanisms and interdependence, heterogeneity as well as spatial and dynamic complexity. The dominant food system includes the multitude of lower-scale complex adaptive systems (i.e., individual farms) while being contained within other complex adaptive systems (i.e., ecological, financial, social, etc.). The latter systems provide conditions to which the FS adapts.
Benckiser and Schnell, 2006; Hendrickson et al., 2008

Tipraqsa, 2006;

Hendrickson et al., 2008; Archer et al., 2018

Hendrickson et al., 2008

Hendrickson et al., 2008; Sassenrath et al., 2009

Altieri et al., 1987; Altieri, 1999

Grey, 2000; McCullough et al., 2008

McCullough et al., 2008; Pengue et al., 2018; Momo-Cabrera et al., 2019

$\mathrm{Xu}$ and Mage, 2001; Garbach et al., 2014

Altieri et al., 1998; Francis et al., 2003; Rosset, 2006; Altieri and Nicholls, 2008; Wezel et al., 2009; Rosset and Martinez-Torres, 2012; Gliessman, 2016, etc.

Ericksen, 2008; Ostrom, 2009; Allen and Prosperi, 2016, etc.

Allen and Prosperi, 2016; Brzezina et al., 2016, etc.

Stroink and Nelson, 2013; Nelson and Stroink, 2014: Nesheim et al., 2015, etc. 
TABLE 1 | Continued

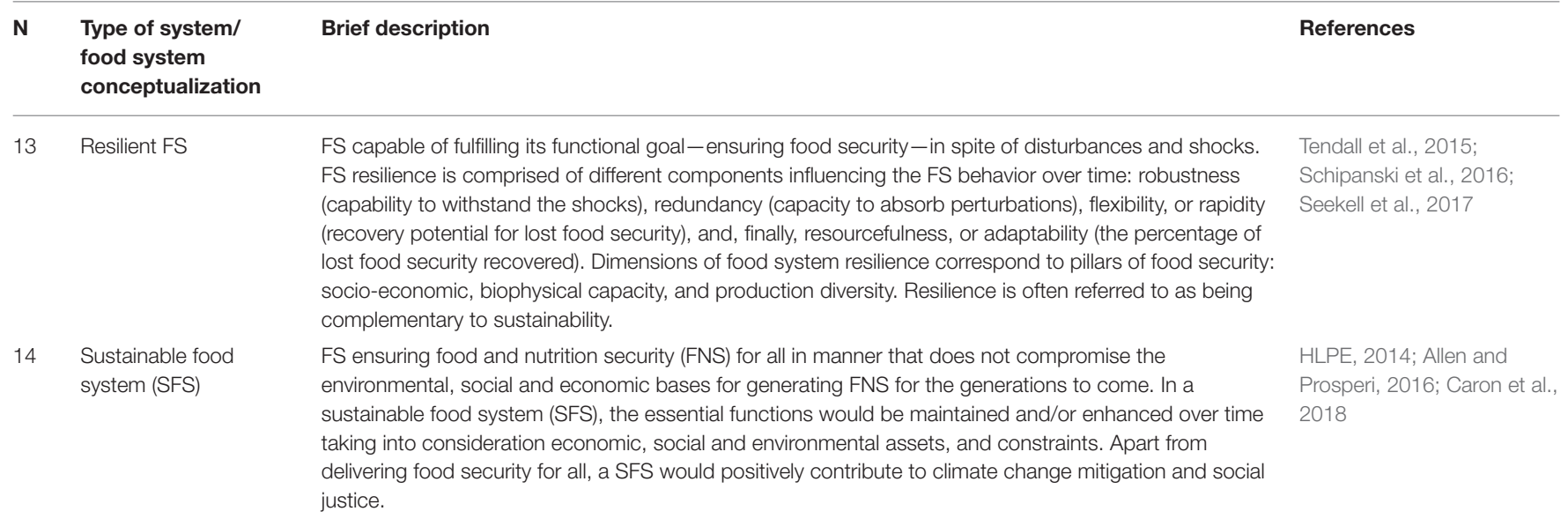

TABLE 2 | Classification of food system outcomes and their discourse framings ${ }^{a}$.

\begin{tabular}{lll}
\hline Discourse framing & $\begin{array}{l}\text { Food system outcomes/performance criteria Concrete outcomes/performance characteristics References } \\
\text { addressed }\end{array}$
\end{tabular}

(Sustainable) food (and FNS, social welfare, environmental security; indirect nutrition) security (FNS) and/or unintentional outcomes; nutritional, environmental, social, and economic outcomes

FSs and global environmental change (GEC) Sustainability

FS performance/metrics for FS (sustainability) assessment

Resilience

Transformation
Sustainable food systems (SFSs) outcomes and attributes; social and ecological performance measures; desired outcomes of a SFS vs. outcomes with unintended negative consequences/unsustainable outcomes; emergent outcomes of a SFS; "sustainability space"

Sustainability outcomes; FS effects: direct and indirect, intended and unintended; sustainable nutrition security performance; holistic SFS performance

Ecological resilience and community resilience; resilience-based FS sustainability; agroecological principles and resilience

Transformational "wedges" for leveraging FS resilience FS outcomes contributing to sustainability, resilience, and equity; intended outcomes; expected outcomes; short-term and long-term outcomes
Food access, availability and utilization, nutrient and diet, socio-cultural well-being (gender equity, respect for community rights, etc.), income and employment, wealth, equity, ecosystem services, ecosystem stability, waste, and loss reduction, food safety, etc. Potential outcomes of climate change mitigation: small-scale livelihoods, nutritional outcomes, food safety, improved pasture quality, and animal health, etc. FNS, equity, accountability, (climate change) resilience, biodiversity, stability, health and well-being, community empowerment, secure livelihoods, agroecological integrity, food sovereignty, food democracy, etc.

Ecosystem stability (including (agro)biodiversity, GHG emissions), resilience, socio-economic benefits and costs/socio-cultural well-being (fair and just conditions for food system actors, wealth distribution and equity, animal welfare), diets and consumption patterns (including dietary diversity), etc.

Enhanced biodiversity and adaptive capacity, human/community health and well-being, self-sufficiency and deliberate learning, food security, human, and ecosystem health

FNS, healthy and nutritious diets, nutritional health and well-being, reduced waste, increased equity and justice, promoted community-based socio-economic development, increased (agro)biodiversity, ecosystems regeneration, climate change mitigation, social justice, etc.
Ericksen, 2008; Ingram, 2011; Ingram et al., 2013; Gustafson et al., 2016; Zurek et al., 2018; Allen et al., 2019

Ericksen, 2008; Ingram, 2011; Niles et al., 2017 2018

Ostrom, 2009; Whitfield et al., 2015; Allen and Prosperi, 2016; Eakin et al., 2017; Gordon et al., 2017; Niles et al., 2017, 2018; Béné et al., 2019

Nesheim et al., 2015; Pelletier, 2015; Allen and Prosperi, 2016; Gustafson et al., 2016; Prosperi et al., 2016; Landert et al., 2017; Zurek et al., 2018

King, 2008; Allen and Prosperi, 2016; Prosperi et al., 2016; Schipanski et al., 2016

Johns et al., 2013; Schipanski et al., 2016: Caron et al., 2018; Lindgren et al., 2018; Vaarst et al., 2018; Bortoletti and Lomax, 2019; Ruben et al., 2019

${ }^{a}$ Results of a systematic literature review on FS outcomes performed between November 1st, 2018 and April 24th, 2019 using databases Web of Science (core collection) and Springerlink. Criteria laid down by the PRISMA method were applied (Moher et al., 2009). The final search string: "food system* outcomes* OR food system* impact* OR food system" consequence*" as a topic; "food system* OR socio-ecological system* OR agri-food system*" in titles of searched articles. Searched publication years: articles published in English language between 2008 and April 2019. Eligibility criteria included: presence of FS outcomes (with at least two different dimensions); FSs approach. $n=26$.

for an active and healthy life" (FAO, 1996). The definition addresses four pillars of food security-physical availability of food, access to food (physical and economic), food utilization and stability of the food supply (FAO, 2008). However, since stability is interlinked with availability and access, sometimes the stability pillar is left out (FAO, 2006; Charlton, 2016). Concurrent GEC discourse examines the complex interactions between FSs and GEC. GEC is defined as changes in the 
environment (both biogeophysical and physical) due to natural causes or human activities (urbanization, deforestation, etc.) (GECAFS, 2008). Not only does this discourse address the two-way interactions between FSs and GEC-the interactions between other components of FSs and GEC as well as the arising feedbacks are also considered (Ericksen, 2008; Ingram, 2011). Particular attention is drawn to the interactions between GEC and food security, with the intent of enhancing food security without compromising the ecosystem services (Ericksen et al., 2010; Ingram, 2011). With weather extremes and increasing temperatures over the past decade the topic of climate change and its interrelations with the FS gained in importance, both within and outside the GEC discourse. Likewise, Niles et al. $(2017,2018)$ present the FS-climate change interplay and show the potential for climate change mitigation and adaptation. The contributions of each of the FS's components as well as systemlevel implications are discussed. Furthermore, some potential outcomes of mitigation opportunities are outlined (see Table 2).

\section{Sustainability and FSs (Sustainability) Performance}

Although sustainability and FSs performance have been identified as separate discourses, they will be discussed jointly due to the fact that the performance assessments attempt to evaluate the FSs sustainability. FS outcomes hence represent a vital part of both discourses. Likewise, Allen and Prosperi (2016) link the notion of sustainability to the outcomes arguing that sustainability "is about maintaining and/or enhancing essential functions or outcomes over time, taking into account environmental, social, and economic constraints and assets." Similarly, Eakin et al. (2017) stress that it seems appealing to define FS sustainability "in terms of maintaining critical system functions." The sustainability discourse is laying down the desired attributes of SFSs. This is done through setting prerequisites, boundaries or, else, making concrete suggestions, which can be ultimately used in performance assessments. Building upon the concept of planetary boundaries, Whitfield et al. (2015) introduce the concept of multidimensional sustainability space incorporating the myriad of ecological and social boundaries acting as "limits of acceptable compromises for a system." The concept is closely related to the concept of resilience-the system's ability to absorb shocks and maintain integrity regenerating after a disturbance, which is why resilience is often listed among the "desired" outcomes of a SFS (Allen and Prosperi, 2016; Béné et al., 2019). This renders resilience to a vital part of FSs performance discourse, where it is viewed as an intrinsic characteristic of the system (Prosperi et al., 2016). Resilience can be also viewed as an important dimension of FSs performance, thereby carrying potential for the identification of variables conducive to ensuring the sustainability of FS outcomes that can be applied in the assessments (Nesheim et al., 2015; Prosperi et al., 2016).

Building on the social-ecological systems research (see Table 1), efforts are made to articulate sustainability performance using concrete attributes and principles. Likewise, Gordon et al. (2017) suggest reinforcing sustainability and health outcomes through improvements in food production and consumption while enhancing the biosphere outcomes could be accomplished through FSs "rewiring." Essentially this conceptualization links biosphere and health outcomes through the FS differentiating between multiple levels within food environment-individual, community, national, and global. This differentiation is also found in conceptualization by Eakin et al. (2017). Here, however, it is taken to the next level bridging natural capital, social welfare, and economic viability, with the evident prominence of the social dimension. The authors identified five FS sustainability attributes for streamlining FS activities toward the "emergent" outcomes: modularity, diversity, innovation, congruence (including socio-cultural aspects) and transparency (Eakin et al., 2017).

Another strand of literature offers concrete metrics for assessing the FSs sustainability performance. For instance, metrics for assessing sustainable FNS are proposed, with the holistic character of the offered approach qualifying it for assessments of the entire FS (Gustafson et al., 2016; Zurek et al., 2018). While the proposed assessment metrics from Gustafson et al. (2016) seem to build upon social, ecological and food security dimensions, the integrated approach offered by Zurek et al. (2018) adds the economic pillar. The latter assessment approach proposes a sustainable FNS visualizer. The tool is based on people, planet and profit approach incorporating equitable conditions, balanced and sufficient diets, reduced environmental impacts and competitiveness of the agri-food business (Zurek et al., 2018). Both assessment approaches explicitly incorporate social well-being and equity as part of the assessment and have the potential of revealing synergies and trade-offs among potential interventions. Furthermore, Gustafson et al. (2016) included animal welfare as an indicator in this category-the issue otherwise insufficiently addressed in the discourses. Finally, combining the variety of existing assessment approaches Landert et al. (2017) propose a holistic method for evaluating the sustainability performance of FS governance. The assessment results display the potential areas of action in four subthemes: good governance, economic resilience, environmental integrity, and social well-being (Landert et al., 2017).

\section{Resilience}

The resilience discourse is closely intertwined with the sustainability narrative and at the same time seems to be deeply entrenched in the performance discourse, as was previously described. However, if the previous discourses viewed resilience rather as a vital system's characteristic, the present discourse incorporates it as a central component and, often, an outcome, which translates into the notion of a resilient FS (see Table 1). Resilience stands for "the ability of a system and its component parts to anticipate, absorb, accommodate, or recover from the effects of a hazardous event in a timely and efficient manner by ensuring the preservation, restoration, or improvement of its essential basic structures and functions" (Allen and Prosperi, 2016). These properties are vital for ensuring the sustainability of FS outcomes. Often resilience is linked to agroecology with a distinct community-based approach (King, 2008; Schipanski et al., 2016). Furthermore, King (2008) differentiates between ecological and community resilience and provides an overview of three models of 
resilience-engineering resilience, ecological resilience, and resilience as adaptive capacity. The latter along with the enhanced socio-ecological links are stressed as crucial FSs attributes for enduring short-term volatility and withstanding pressures (Schipanski et al., 2016).

\section{Transformation}

This discourse looks at possible transition pathways to SFSs. Although the vision of a transformed FS as well as the concrete suggestions varies, certain commonalities stand out. For instance, community-based approaches underpinned by agroecological and city-region concepts are offered as a transformation strategy (King, 2008; Schipanski et al., 2016; Vaarst et al., 2018). These approaches offer potential for facilitating the transition to a regenerative and resilient, agrobiodiverse, food secure, equitable and healthy FS with higher well-being of rural communities (King, 2008; Schipanski et al., 2016; Vaarst et al., 2018). Moreover, a stronger focus on the interplay of resilience and institutions through agroecological approach is put forward to better address issues like the right and access to natural resources and ecosystems services (Niles et al., 2017; Vaarst et al., 2018). Due to the fact that agroecology ties in with food sovereignty, the issues of equitability and existing power relations could be simultaneously tackled resulting in positive implications for agrobiodiversity and FNS (Schipanski et al., 2016; Vaarst et al., 2018; see concept 9 in Table 2). The next commonality in the discourse is the presence of resilience concept, which has been observed in the previous narratives as well. Transformation discourse, however, incorporates resilience as one of the transformative principles, or attributes (Niles et al., 2017; Vaarst et al., 2018; Ruben et al., 2019). Here, an important differentiation has been made by Vaarst et al. (2018). The authors stressed various levels of resilience in ecological, institutional and social realms as well as at individual and populations level suggesting treating health as resilience. Moreover, multiple publications emphasize an important contribution to various levels of resilience including equity, inclusiveness, health, but also agrobiodiversity and economic growth through a stronger focus on smallholders and traditional communities (Johns et al., 2013; Schipanski et al., 2016; Niles et al., 2017). The latter is intertwined with addressing the rural-urban links through the renaissance of rural territories (Caron et al., 2018). This should enhance the inclusiveness aspect and improve FNS, while enhancing environmental protection, social welfare and economic growth (Johns et al., 2013; Caron et al., 2018; Vaarst et al., 2018). Simultaneously, contribution to at least seven goals of the 2030 Agenda might be achieved (Caron et al., 2018). Another important leverage point for the transformation is seen through the adoption of sustainable consumption patterns. This could bring in far-reaching effects benefiting health and all the sustainability dimensions (Gordon et al., 2017; Caron et al., 2018; Lindgren et al., 2018). Finally, collaborative policymaking and governance for SFSs is vital (Bortoletti and Lomax, 2019). It should be based on a systems approach, a long-term outlook and the emphasis on outcomes as a starting point of transformation (Bortoletti and Lomax, 2019).

\section{DISCUSSION}

To optimize their performance and balance the outcomes, current FSs need to be transformed. A SFS should provide FNS for all while ensuring socio-cultural well-being within the planetary boundaries. This is a challenging endeavor, not least due to the existing feedbacks and trade-offs. This mini-review identified six FS outcomes discourses seeking to uncover their potential for FSs transformation. All discourses emphasize a vital role of systems approach, stressing the importance of existing interactions, feedback mechanisms and potential tradeoffs. This should necessarily find reflection in transformation strategies. The FNS and GEC discourses bring forward the FNS as a principal FS outcome while addressing the interactions with GEC and the related environmental security outcomes. Sustainability and FSs performance discourses lay down specific properties and attributes making up a set of "desired" outcomes of SFSs. Moreover, quite promising multidimensional indicators and holistic assessment tools are suggested. However, the focus is placed on measuring sustainability using quantifiable parameters. The eponymous discourse addresses resilience as a property or an outcome of SFSs often linking it to agroecology. Resilience, however, is present in other discourses as well suggesting that it should deserve a closer consideration for the transformation. As an intrinsic system's characteristic and a transformative principle, resilience bears potential for leveraging the "intended" outcomes. Here, agroecological and city-region approaches could unlock potential of a truly systemic approach to FS outcomes. A focus on smallholders and rural communities allows these approaches to activate synergetic outcomes. Coupled with dietary changes, this could bring in a multitude of "desired" outcomes simultaneously achieving several SDGs.

\section{CONCLUSION}

FS outcomes could act as a transformation gate capable of aligning FSs with the 2030 Agenda. The mini-review uncovered some important interactions between the FS outcomes discourses suggesting that for a successful transformation, it would be essential to treat outcomes systemically. Important leverage points for transforming FSs could be found in strengthening rural-urban links, a stronger emphasis on smallholders and rural communities as well as dietary shifts. Agroecology and cityregion approaches with their essential contributions in these realms might act as potential facilitators of transformation. A few points, however, deserve more attention. First, socio-cultural appropriateness of dietary shifts should not be neglected since it might impose significant challenges to transformation efforts. In terms of assessing the FSs performance, the technocratic character of existing assessment frameworks might not allow for a truly systemic and inclusive approach to FSs transformation. Having certain descriptive performance attributes could help to fully grasp the complexity of FSs performance, owing to its holistic character. At the same time, inclusiveness of various stakeholders in transformation strategies will be better addressed allowing for reaping the benefits of traditional knowledge and genuinely sustainable practices. 


\section{AUTHOR CONTRIBUTIONS}

A systematic literature review was conducted by LS under the supervision of JK. LS wrote the present manuscript. BF-L revised it as well as its edited version. All authors reviewed the final work and approved the submitted version.

\section{FUNDING}

This review was carried out within the framework of the cooperative $\mathrm{PhD}$ programme Food Economy and

\section{REFERENCES}

Allen, T., and Prosperi, P. (2016). Modeling sustainable food systems. Environ. Manag. 57, 956-975. doi: 10.1007/s00267-016-0664-8

Allen, T., Prosperi, P., Cogill, B., Padilla, M., and Peri, I. (2019). A delphi approach to develop sustainable food system metrics. Soc. Indic. Res. 141, 1307-1339. doi: 10.1007/s11205-018-1865-8

Altieri, M. A. (1999). Applying agroecology to enhance the productivity of peasant farming systems in Latin America. Environ. Dev. Sust. 1, 197-217. doi: 10.1023/A:1010078923050

Altieri, M. A., Anderson, M. K., and Merrick, L. C. (1987). Peasant agriculture and the conservation of crop and wild plant resources. Conserv. Biol. 1, 49-58. doi: 10.1111/j.1523-1739.1987.tb00008.x

Altieri, M. A., and Nicholls, C. I. (2008). Scaling up agroecological approaches for food sovereignty in Latin America. Development 51, 472-480. doi: $10.1057 / \mathrm{dev} .2008 .68$

Altieri, M. A., Rosset, P., and Thrupp, L. A. (1998). The Potential of Agroecology to Combat Hunger in the Developing World. IFPRI. Available online at: https://www.ifpri.org/publication/potential-agroecology-combathunger-developing-world (accessed August 12, 2020).

Archer, D. W., Franco, J. G., Halvorson, J. J., and Pokharel, K. P. (2018). "Integrated," in Encyclopedia of Ecology, 2nd Edn. ed. B. Fath (Oxford: Elsevier), 508-514. doi: 10.1016/B978-0-12-409548-9.10562-7

Benckiser, G., and Schnell, S. (2006). "Introduction," in Biodiversity in Agricultural Production Systems, eds G. Benckiser and S. Schnell (Boca Raton, FL: CRC Press), xvii-1.

Béné, C., Oosterveer, P., Lamotte, L., Brouwer, I. D., Haan, S., de Prager, S. D., et al. (2019). When food systems meet sustainability - current narratives and implications for actions. World Dev. 113, 116-130. doi: 10.1016/j.worlddev.2018.08.011

Bortoletti, M., and Lomax, J. (2019). Collaborative Framework for Food Systems Transformation. A Multi-Stakeholder Pathway for Sustainable Food Systems. UNEP.

Brzezina, N., Kopainsky, B., and Mathijs, E. (2016). Can organic farming reduce vulnerabilities and enhance the resilience of the European food system? A critical assessment using system dynamics structural thinking tools. Sustainability 8:971. doi: 10.3390/su8100971

Caron, P., Ferrero Y de Loma-Osorio, G., Nabarro, D., Hainzelin, E., Guillou, M., Andersen, I., et al. (2018). Food systems for sustainable development: proposals for a profound four-part transformation. Agron. Sustain. Dev. 38:41. doi: $10.1007 / \mathrm{s} 13593-018-0519-1$

Charlton, K. E. (2016). Food security, food systems and food sovereignty in the 21 st century: a new paradigm required to meet sustainable development goals. Nutr. Diet. 73, 3-12. doi: 10.1111/1747-0080.12264

Chase, L., and Grubinger, V. (2014). Food, Farms, and community: Exploring Food Systems. New Hampshire: University of New Hampshire Press.

Eakin, H., Connors, J. P., Wharton, C., Bertmann, F., Xiong, A., and Stoltzfus, J. (2017). Identifying attributes of food system sustainability: emerging themes and consensus. Agric. Hum. Values 34, 757-773. doi: $10.1007 / \mathrm{s} 10460-016-9754-8$

EEA (2017). Food in a Green Light: A Systems Approach to Sustainable Food. Copenhagen: Publications Office of the European Union.
Technology of the University of Kassel and the Fulda University of Applied Sciences and was financially supported by the Federal Hessian Ministry of Science and Art.

\section{ACKNOWLEDGMENTS}

The authors thank the reviewers and associate editor for their valuable comments and suggestions that helped to improve the manuscript.

Ericksen, P., Stewart, B., Dixon, J., Barling, D., Loring, P., Anderson, M., et al. (2010). "The value of a food system approach," in Food Security and Global Environmental Change, eds J. Ingram and P. Ericksen (London: Earthscan), 25-45.

Ericksen, P. J. (2008). Conceptualizing food systems for global environmental change research. Glob. Environ. Change 18, 234-245. doi: 10.1016/j.gloenvcha.2007.09.002

FAO (1996). Rome Declaration on World Food Security and World Food Summit Plan of Action. Rome: FAO. Available online at: http://www.fao.org/3/w3613e/ w3613e00.htm (accessed July 26, 2020).

FAO (2006). Food Security. Rome: FAO.

FAO (2008). An Introduction to the Basic Concepts of Food Security. Food Security Information for Action: Practical Guides. Rome: EC - FAO Food Security Programme.

FAO (2018). Transforming Food and Agriculture to Achieve the SDGs: 20 Interconnected Actions to Guide Decision-Makers. Rome: FAO.

FAO, IFAD, UNICEF, WFP, and WHO (2020). "The state of food security and nutrition in the world 2020," in Transforming Food Systems for Affordable Healthy Diets. Progress Towards Hunger and Food Insecurity Targets, ed C. Cafiero (Rome: FAO), 3-25.

Francis, C., Lieblein, G., Gliessman, S., Breland, T. A., Creamer, N., Harwood, R. L., et al. (2003). Agroecology: the ecology of food systems. J. Sustain. Agric. 22, 99-118. doi: 10.1300/J064v22n03_10

Garbach, K., Milder, J. C., Montenegro, M., Karp, D. S., and DeClerck, F. A. J. (2014). "Biodiversity and ecosystem services in agroecosystems," in Encyclopedia of Agriculture and Food Systems, Vol. 2, ed. N. K. van Alfen (London: Academic Press), 21-41. doi: 10.1016/B978-0-444-52512-3.00013-9

GECAFS (2008). GECAFS Indo-Gangetic Plain Science Plan and Implementation Strategy. Oxford: GECAFS.

Gliessman, S. (2016). Transforming food systems with agroecology. Agroecol. Sustain. Food Syst. 40, 187-189. doi: 10.1080/21683565.2015. 1130765

Gordon, L. J., Bignet, V., Crona, B., Henriksson, P. J. G., van Holt, T., Jonell, M., et al. (2017). Rewiring food systems to enhance human health and biosphere stewardship. Environ. Res. Lett. 12:100201. doi: 10.1088/1748-9326/aa81dc

Grey, M. A. (2000). The industrial food stream and its alternatives in the United States: an introduction. Soc. Appl. Anthropol. 59, 143-150. doi: 10.17730/humo.59.2.xm3235743p6618j3

Gustafson, D., Gutman, A., Leet, W., Drewnowski, A., Fanzo, J., and Ingram, J. (2016). Seven food system metrics of sustainable nutrition security. Sustainability 8:196. doi: 10.3390/su8030196

Hendrickson, J. R., Hanson, J. D., Tanaka, D. L., and Sassenrath, G. (2008). Principles of integrated agricultural systems: introduction to processes and definition. Renew. Agric. Food Syst. 23, 265-271. doi: $10.1017 /$ S1742170507001718

HLPE (2014). Food Losses and Waste in the Context of Sustainable Food Systems: A Report by the High Level Panel of Experts on Food Security and Nutrition of the Committee on World Food Security. Rome: HLPE.

Ingram, J. (2011). A food systems approach to researching food security and its interactions with global environmental change. Food Sec. 3, 417-431. doi: 10.1007/s12571-0110149-9 
Ingram, J. S. I., Wright, H. L., Foster, L., Aldred, T., Barling, D., Benton, T. G., et al. (2013). Priority research questions for the UK food system. Food Sec. 5, 617-636. doi: 10.1007/s12571-013-0294-4

IPBES (2019). "Summary for policymakers of the global assessment report on biodiversity and ecosystem services of the intergovernmental," in Science-Policy Platform on Biodiversity and Ecosystem Services. eds S. Díaz, J. Settele, E. S. Brondízio, H. T. Ngo, M. Guèze, and J. Agard, (Bonn: IPBES secretariat), 10-19.

Johns, T., Powell, B., Maundu, P., and Eyzaguirre, P. B. (2013). Agricultural biodiversity as a link between traditional food systems and contemporary development, social integrity and ecological health. J. Sci. Food Agric. 93, 3433-3442. doi: 10.1002/jsfa.6351

King, C. A. (2008). Community resilience and contemporary agri-ecological systems: reconnecting people and food, and people with people. Syst. Res. 25, 111-124. doi: 10.1002/sres.854

Landert, J., Schader, C., Moschitz, H., and Stolze, M. (2017). A holistic sustainability assessment method for Urban food system governance. Sustainability 9:490. doi: 10.3390/su9040490

Lindgren, E., Harris, F., Dangour, A. D., Gasparatos, A., Hiramatsu, M., Javadi, F., et al. (2018). Sustainable food systems-a health perspective. Sustain. Sci. 13, 1505-1517. doi: 10.1007/s11625-018-0586-x

MacDonald, R., and Reitmeier, C. (2017). Understanding Food Systems: Agriculture, Food Science, and Nutrition in the United States. London: Academic Press. doi: 10.1016/B978-0-12-804445-2.00012-0

McCullough, E. B., Pingali, P. L., and Stamoulis, K. G. (2008). "Small farms and the transformation of food systems: an overview," in The Transformation of Agri-Food Systems: Globalization, Supply Chains and Smallholder Farmers, eds E. B. McCullough, P. L. Pingali, and K. G. Stamoulis (London: Earthscan and FAO), 3-47.

Moher, D., Shamseer, K., Clarke, M., Ghersi, D., Liberati, A., Petticrew, M., et al. (2009). Preferred reporting items for systematic review and meta-analysis protocols (PRISMA-P) 2015 statement. Syst. Rev. 2015 4:1. doi: 10.1186/2046-4053-4-1

Momo-Cabrera, P., Ortiz-Andrellucchi, A., and Serra-Majem, L. (2019). "Food systems," in Encyclopedia of Food Security and Sustainability, Vol. 2, Food Security, Nutrition and Health, eds P. Ferranti, E. M. Berry, and J. R. Anderson (Oxford: Elsevier), 206-214. doi: 10.1016/B978-0-08-100596-5.22032-5

Moscatelli, S., El Bilali, H., Gamboni, M., and Capone, R. (2016). Towards sustainable food systems: a holistic, interdisciplinary and systemic approach. Int. J. AgroFor 1, 103-112. doi: 10.7251/AGRENG1601103M

Nelson, C. H., and Stroink, M. L. (2014). Accessibility and viability: a complex adaptive systems approach to a wicked problem for the local food movement. J. Agric. Food Syst. Commun. Dev. 4, 191-206. doi: 10.5304/jafscd.2014.044.016

Nesheim, M. C., Oria, M., and Yih, P. T. (2015). A Framework for Assessing the Effects of the Food System. Washington, DC: National Academies Press; National Research Council; Institute of Medicine.

Niles, M., Esquivel, J., Ahuja, R., and Mango, N. (2017). Climate Change \& Food Systems: Assessing Impacts and Opportunities. Washington, DC: Meridian Institute.

Niles, M. T., Ahuja, R., Barker, T., Esquivel, J., Gutterman, S., Heller, M. C., et al. (2018). Climate change mitigation beyond agriculture: a review of food system opportunities and implications. Renew. Agric. Food Syst. 33, 297-308. doi: $10.1017 /$ S1742170518000029

Ostrom, E. (2009). A general framework for analyzing sustainability of socialecological systems. Science 325, 419-422. doi: 10.1126/science.1172133

Pelletier, N. (2015). Life cycle thinking, measurement and management for food system sustainability. Environ. Sci. Technol. 49, 7515-7519. doi: 10.1021/acs.est.5b00441

Pengue, W., Gemmill-Herren, B., Balázs, B., Ortega, E., Viglizzo, E., Acevedo, F., et al. (2018). "Eco-agri-food systems: today's realities and tomorrow's challenges," in TEEB for Agriculture \& Food: Scientific and Economic Foundations, eds J. Fanzo, and P. Koohafkan (Geneva: UN Environment), 57-109.

Petticrew, M., and Roberts, H. (2006). Systematic Reviews in the Social Sciences: A Practical Guide. Oxford: Blackwell Publishing. doi: 10.1002/978047 0754887

Prosperi, P., Allen, T., Cogill, B., Padilla, M., and Peri, I. (2016). Towards metrics of sustainable food systems: a review of the resilience and vulnerability literature. Environ. Syst. Decis. 36, 3-19. doi: 10.1007/s10669-016-9584-7

Rosset, P. M. (2006). "Moving forward: agrarian reform as part of food sovereignty," in Promised Land: Competing Visions of Agrarian Reform, eds
P. Rosset, R. Patel, and M. Courville (New York, NY: Institute for Food and Development Policy), 301-321.

Rosset, P. M., and Martinez-Torres, M. E. (2012). Rural social movements and agroecology: context, theory, and process. Ecol. Soc. 17:17. doi: 10.5751/ES-05000-170317

Ruben, R., Verhagen, J., and Plaisier, C. (2019). The Challenge of food systems research: what difference does it make? Sustainability 11:171. doi: $10.3390 /$ su11010171

Sassenrath, G. F., Hanson, J. D., Hendrickson, J. R., Archer, D. W., Halloran, J. F., and Steiner, J. J. (2009). "Principles of dynamic integrated agricultural systems: lessons learned from an examination of southeast production systems," in Sustainable Ecosystem Management: Integrating Ecology, Economics, and Society, eds P. J. Bohlen and G. House (Boca Raton, FL: CRC Press), 259-271.

Schipanski, M. E., MacDonald, G. K., Rosenzweig, S., Chappell, M. J., Bennett, E. M., Kerr, R. B., et al. (2016). Realizing resilient food systems. BioScience 66, 600-610. doi: 10.1093/biosci/biw052

Seekell, D., Carr, J., Dell'Angelo, J., D’Odorico, P., Fader, M., Gephart, J., et al. (2017). Resilience in the global food system. Environ. Res. Lett. 12:025010. doi: 10.1088/1748-9326/aa5730

Stroink, M. L., and Nelson, C. H. (2013). Complexity and food hubs: five case studies from Northern Ontario. Local Environ. 18, 620-635. doi: 10.1080/13549839.2013.798635

Tendall, D. M., Joerin, J., Kopainsky, B., Edwards, P., Shreck, A., Le, Q. B., et al. (2015). Food system resilience: defining the concept. Glob. Food Secur. 6, 17-23. doi: 10.1016/j.gfs.2015.08.001

Tipraqsa, P. (2006). "Opportunities and constraints of integrated farming system in Northeast Thailand. A case study of the huai nong ian catchment, khon kaen province," in Ecology and Development Series 35, Center for Development Research (Bonn: Cuvillier Verlag).

UNEP (2016). "Chapter 2: A food systems approach to natural resource use," in A Report of the Working Group on Food Systems of the International Resource Panel. eds H. Westhoek, J. Ingram, S. Van Berkum, L. Özay, and M. Hajer. 28-35.

Vaarst, M., Escudero, A. G., Chappell, M. J., Brinkley, C., Nijbroek, R., Arraes, N. A. M., et al. (2018). Exploring the concept of agroecological food systems in a city-region context. Agroecol. Susta. Food Syst. 42, 686-711. doi: 10.1080/21683565.2017.1365321

Vermeulen, S. J., Campbell, B. M., and Ingram, J. S. I. (2012). Climate change and food systems. Annu. Rev. Environ. Resourc. 37, 195-222. doi: 10.1146/annurev-environ-020411-130608

Wezel, A., Bellon, S., Doré, T., Francis, C., Vallod, D., and David, C. (2009). Agroecology as a science, a movement and a practice. A review. Agron. Sustain. Dev. 29, 503-515. doi: 10.1051/agro/2009004

Whitfield, S., Benton, T. G., Dallimer, M., Firbank, L. G., Poppy, G. M., Sallu, S. M., et al. (2015). Sustainability spaces for complex agri-food systems. Food Sec. 7, 1291-1297. doi: 10.1007/s12571-015-0512-3

Whitmee, S., Haines, A., Beyrer, C., Boltz, F., Gapon, A. G., Ferreira de Souza Dias, B., et al. (2015). Safeguarding human health in the Anthropocene epoch: report of the rockefeller foundation-lancet commission on planetary health. Lancet 386, 1973-2028. doi: 10.1016/S0140-6736(15) 60901-1

Xu, W., and Mage, J. A. (2001). A review of concepts and criteria for assessing agroecosystem health including a preliminary case study of southern Ontario. Agricult. Ecosyst. Environ. 83, 215-233. doi: 10.1016/S0167-8809(00) 00159-6

Zurek, M., Hebinck, A., Leip, A., Vervoort, J., Kuiper, M., Garrone, M., et al. (2018). Assessing sustainable food and nutrition security of the EU food system - an integrated approach. Sustainability 10:4271. doi: 10.3390/su10114271

Conflict of Interest: The authors declare that the research was conducted in the absence of any commercial or financial relationships that could be construed as a potential conflict of interest.

Copyright (C) 2020 Stefanovic, Freytag-Leyer and Kahl. This is an open-access article distributed under the terms of the Creative Commons Attribution License (CC BY). The use, distribution or reproduction in other forums is permitted, provided the original author(s) and the copyright owner(s) are credited and that the original publication in this journal is cited, in accordance with accepted academic practice. No use, distribution or reproduction is permitted which does not comply with these terms. 